\title{
Electrical Parameters of the Erbium Oxide MOS Capacitor for Different Frequencies
}

\author{
Berk Morkoc $^{1}$, Aysegul Kahraman ${ }^{1 *}$, Aliekber Aktag ${ }^{2,3}$, Ercan Yilmaz $^{2,3}$ \\ ${ }^{1}$ Physics Department, Faculty of Arts and Sciences, Bursa Uludag University, 16059, Bursa, Turkey \\ ${ }^{2}$ Physics Department, Faculty of Arts and Sciences, Bolu Abant Izzet Baysal University, 14280, Bolu, Turkey \\ ${ }^{3}$ Center for Nuclear Radiation Detectors Research and Applications, Bolu Abant Izzet Baysal University, 14280, \\ Bolu, Turkey \\ *aysegulk@uludag.edu.tr
}

Received: 14 September 2018

Accepted: 17 June 2019

DOI: $10.18466 /$ cbayarfbe.460022

\begin{abstract}
Electrical parameters of Erbium Oxide $\left(\mathrm{Er}_{2} \mathrm{O}_{3}\right)$ MOS capacitors depending on frequency were investigated deeply, in this paper. $\mathrm{Er}_{2} \mathrm{O}_{3}$ layers were deposited on $\mathrm{p}-\mathrm{Si}$ substrates with (100) oriented using $\mathrm{RF}-$ magnetron sputtering method. The films were annealed at $500{ }^{\circ} \mathrm{C}$ in $\mathrm{N}_{2}$ environment. $\mathrm{C}-\mathrm{V}$ characteristic changes reduce with increasing frequency. $\mathrm{G} / \omega-\mathrm{V}$ characteristic variations show different behavior between $10-250 \mathrm{kHz}$ and $250 \mathrm{kHz}-1 \mathrm{MHz}$. It is thought that these different behaviors are caused by interface states between silicon and $\mathrm{Er}_{2} \mathrm{O}_{3}$ layer, series resistance $\left(\mathrm{R}_{\mathrm{s}}\right)$ effects and the relaxation time of trapped states. The $R_{s}$ values calculated by the $C_{m a}$ and $G_{m a}$ values at the high frequency and decrease with rising frequency. Then, $\mathrm{C}_{\mathrm{c}}-\mathrm{V}$ and $\mathrm{G}_{\mathrm{c}} / \omega-\mathrm{V}$ characteristic curves were measured and compared to first measurements. In addition, interface state density $\left(\mathrm{D}_{\mathrm{it}}\right)$, diffusion potential $\left(\mathrm{V}_{\mathrm{D}}\right)$, and barrier height $\left(\Phi_{\mathrm{B}}\right)$ were calculated and these results demonstrate similar behaviors.
\end{abstract}

Keywords: $\mathrm{Er}_{2} \mathrm{O}_{3}$, MOS, Capacitor, Interface states, Series resistance.

\section{Introduction}

Electrical characteristics of Metal/Oxide/ Semiconductor (MOS) based devices depend primarily on the features of the dielectric substance used as the sensitive region/gate oxide layer, and the dielectric/substrate interface quality. The silicon dioxide $\left(\mathrm{SiO}_{2}\right)$ layer was commonly used as gate oxide layer in the MOS-based device. However, due to the ever-smaller size of the microelectronic device, a thinner $\mathrm{SiO}_{2}$ layer is placed on the MOS-based structures, which lead to an increase in the leakage current of the transistor. On the other hand, alternative gate oxide layers are also needed to improve the sensitivity of MOS-based radiation sensors in low doses $(<10 \mathrm{mGy})[1,2]$. For these reasons, the researchers have begun to investigate the alternative materials to be used as gate oxide layer to solve these problems, and the studies have focused on the high-k dielectrics with the high charge storage capacity in recent years. The interface quality in the middle of dielectric material and $\mathrm{Si}$ substrate and occurring interface trap charge density as depending on this can lead to problems for high-k MOS structures. Electron trap centers can be formed at the interface and nearinterface region in the oxide as a result of the lattice mismatch between the high-k dielectric and $\mathrm{Si}$. The electrons trapped in these centers lead to the $\mathrm{V}_{\mathrm{fb}}$ (flat band voltage) shift of a MOS capacitor fabricated on the $\mathrm{p}-\mathrm{Si}$ substrate to the right side $[3,4]$. Another problem is the undesired low-k $\mathrm{SiO}_{\mathrm{x}}$ parasitic interface formed between the high-k dielectric and Si. Since this layer has a low dielectric constant, it gives rise to a drop in the capacitance values and this causes the dielectric constant calculated for the oxide to be below the expected value [5].

The $\mathrm{C}-\mathrm{V}$ and $\mathrm{G} / \omega-\mathrm{V}$ characteristic curves of a MOS capacitor can be easily influenced by frequencydependent interface trap charges and series resistance effects. At this point, the electrical characteristics of a fabricated MOS capacitor need to be examined in detail. The $\mathrm{Er}_{2} \mathrm{O}_{3}$ (erbium oxide) as a rare earth oxide have a large band gap (7.6 eV) [6] and conduction band offset (3.5 eV) [7] which makes it attractive for MOS-based devices. On the other hand, the probability of a silicatelike build-up at the interface after post-deposition annealing is lower compared to other rare earth oxides. In present study, $\mathrm{Er}_{2} \mathrm{O}_{3} \mathrm{MOS}$ capacitors whose electrical properties vary with frequency and applied voltage are investigated. $\mathrm{C}-\mathrm{V}$ and $\mathrm{G} / \omega-\mathrm{V}$ measurements of the generated $\mathrm{Er}_{2} \mathrm{O}_{3}$ MOS capacitor were measured at different frequencies and then some electrical parameters of the device such as interface state density $\left(D_{i t}\right)$, barrier height $\left(\varphi_{\mathrm{B}}\right)$, acceptor concentration $\left(\mathrm{N}_{\mathrm{A}}\right)$ and energy difference between the valence band and Fermi level $\left(\mathrm{E}_{\mathrm{F}}\right)$ were calculated. 


\section{Materials and Methods}

The $\mathrm{Er}_{2} \mathrm{O}_{3}$ films were growth on $\mathrm{p}-\mathrm{Si}$ with (100) oriented substrate by radio frequency sputtering ( $\mathrm{RF}$-sputtering) system using a 4" $99.99 \%$ pure erbium target. Before the growth of $\mathrm{Er}_{2} \mathrm{O}_{3}$ layer, the $\mathrm{Si}$ substrates were decontaminated with standard Radio Corporation of America (RCA) cleaning procedure. Then, the sanitized wafers were translocated to the sputtering chamber and the pressure of the chamber was configured $6 \times 10^{-4} \mathrm{~Pa}$. A pre-sputter processing was applied for one hour at $300 \mathrm{~W}$ power to clean out any potential pollution on the target. After the pre-sputtering process, the $\mathrm{Er}_{2} \mathrm{O}_{3}$ deposition was carried out using Argon gas with a flow rate of 16 $\mathrm{sccm}$ at $300 \mathrm{~W}$ power and a gas pressure of $1 \mathrm{~Pa}$. Following deposition, the $\mathrm{Er}_{2} \mathrm{O}_{3}$ thin films were annealed at $500{ }^{\circ} \mathrm{C}$ for thirty minutes. In the meanwhile, the flow rate under $\mathrm{N}_{2}$ ambient was $1000 \mathrm{sccm}$. In the measurement using the reflectometer, the thickness of the films was determined to be approximately $254 \mathrm{~nm}$. The front and back contacts were produced with aluminium (Al) by a sputtering process. However, the front $\mathrm{Al}$ electrodes were produced with the aid of a shadow mask. This mask consists of $1.5 \mathrm{~mm}$ circular points.

\section{Results and Discussion}

Capacitance-voltage $(\mathrm{C}-\mathrm{V})$ and conductance-voltage $(\mathrm{G} / \omega-\mathrm{V})$ characteristics were obtained for seven different frequencies between $10 \mathrm{kHz}$ and $1 \mathrm{MHz}$ at ambient temperature to determine the electrical parameters of $\mathrm{Er}_{2} \mathrm{O}_{3} \mathrm{MOS}$ capacitor. Figure 1 shows the $\mathrm{C}-\mathrm{V}$ and $\mathrm{G} / \omega-$ $\mathrm{V}$ curves of $\mathrm{Er}_{2} \mathrm{O}_{3}$ capacitor for each frequency. These curves vary as depending on the A.C. voltage frequency can be easily noticed.

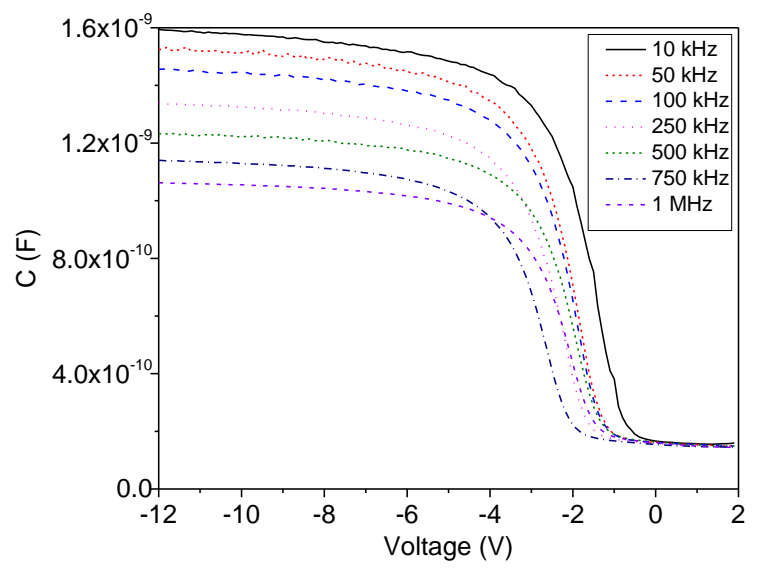

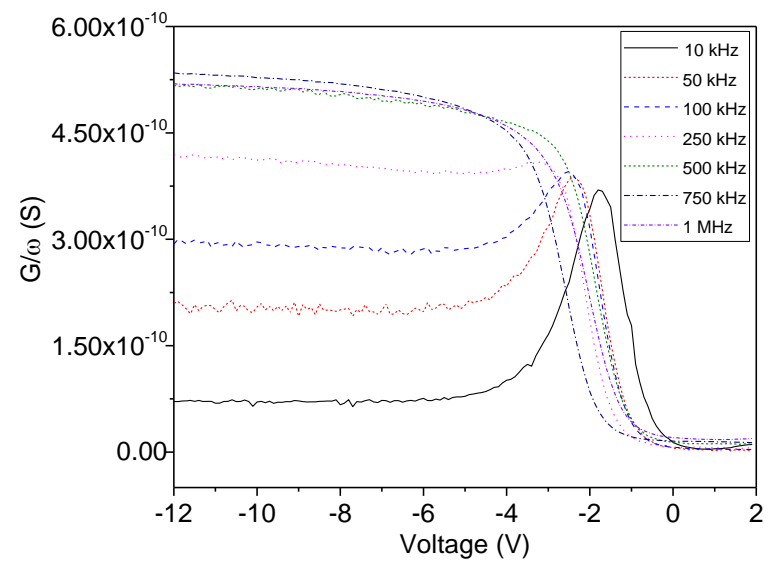

Figure 1. $\mathrm{C}-\mathrm{V}$ and $\mathrm{G} / \omega-\mathrm{V}$ characteristics of $\mathrm{Er}_{2} \mathrm{O}_{3} \mathrm{MOS}$ capacitor in various frequency range from $10 \mathrm{kHz}$ to 1 $\mathrm{MHz}$.

The oxide capacitance $\left(\mathrm{C}_{\mathrm{ox}}\right)$ in MOS structures can be expressed as [8]

$$
C_{o x}=A \frac{\varepsilon_{0} \varepsilon_{o x}}{d}
$$

where $\mathrm{A}\left(1.7671 \times 10^{-6} \mathrm{~m}^{2}\right)$ is capacitor area, $\varepsilon_{0}\left(8.85 \times 10^{-}\right.$ $\left.{ }^{12} \mathrm{~F} . \mathrm{m}^{-1}\right)$ is vacuum permittivity, $\mathrm{d}(125 \mathrm{~nm})$ is the $\mathrm{Er}_{2} \mathrm{O}_{3}$ oxide thickness between metal and semiconductor layers and $\varepsilon_{\mathrm{ox}}$ is the dielectric permittivity of oxide. Using Fig. 1 , the $\mathrm{C}_{\mathrm{ox}}$ value determined from the strong accumulation region for $1 \mathrm{MHz}$ was found to be $1.05 \times 10^{-9} \mathrm{~F}$. So, using the Eq. (1), the dielectric constant of $\mathrm{Er}_{2} \mathrm{O}_{3}$ was calculated as 8.39. In the literature, the dielectric constant of $\mathrm{Er}_{2} \mathrm{O}_{3}$ is reported in the range of $10-14[6,7]$. This result shows that the obtained dielectric constant is lower than expected value. According to the Fig. 1, the capacitance values in the accumulation region decrease with ever-rising frequency. The most probable cause for this is time-dependent interface states $\left(\mathrm{N}_{\mathrm{it}}\right)$ [8]. Also, as apparent in Fig. 1, the flat band and mid-gap voltages are shifted in the negative direction on the voltage axis depending on the frequency. This may be due to the interface states and the series resistance effect $[9,10]$.

Another important parameter used to examine the interfacial quality of MOS capacitors is conductance [11]. The conductance, which is caused by the interaction between the interface states and the majority carriers, occurs when a weak A.C. signal is applied to the MOS capacitor [12]. The measured conductance values increase with increasing frequencies. Nonetheless, the $\mathrm{G} / \omega-\mathrm{V}$ curve peaks measured between $10 \mathrm{kHz}$ and 250 $\mathrm{kHz}$ moved to lower voltages with increasing frequency, the $\mathrm{G} / \omega-\mathrm{V}$ curves measured from $500 \mathrm{kHz}$ to $1 \mathrm{MHz}$ did not include conductance peak. This behavior may be related to the series resistance occurring due to using back side of the Si layer as a metal contact, the relaxation time of the trapped states and the interface dielectric layer [13].

By using the capacitance and conductivity values obtained from the curves, a series resistance $\left(\mathrm{R}_{\mathrm{s}}\right)$ calculation can be made in MOS structures. The 
admittance $\left(\mathrm{Y}_{\mathrm{ma}}\right.$ ) might be reached through the agency of parallel RC circuit [14],

$$
Y_{m a}=G_{m a}+j \omega C_{m a}
$$

From here, $R_{s}$ is defined as [15],

$$
R_{s}=\frac{G_{m a}}{\left(G_{m a}\right)^{2}+\left(\omega C_{m a}\right)^{2}}
$$

where $\mathrm{C}_{\mathrm{ma}}$ is the measured capacitance from the strong accumulation region, while $\mathrm{G}_{\mathrm{ma}}$ is the measured conductance from the same region. According to the Table 1, the $R_{s}$ values calculated using Eq. (3) decrease with increscent frequency values. The reason for this behavior of $\mathrm{R}_{\mathrm{s}}$ may be that the trapped charges are recombined depending on the applied voltage. The voltage-dependent $R_{\mathrm{S}}$ values are also shown in Fig. 2 . Particularly, it is seen that the series resistance effect at low frequencies causes a serious deviation from ideal MOS capacitor characteristics.

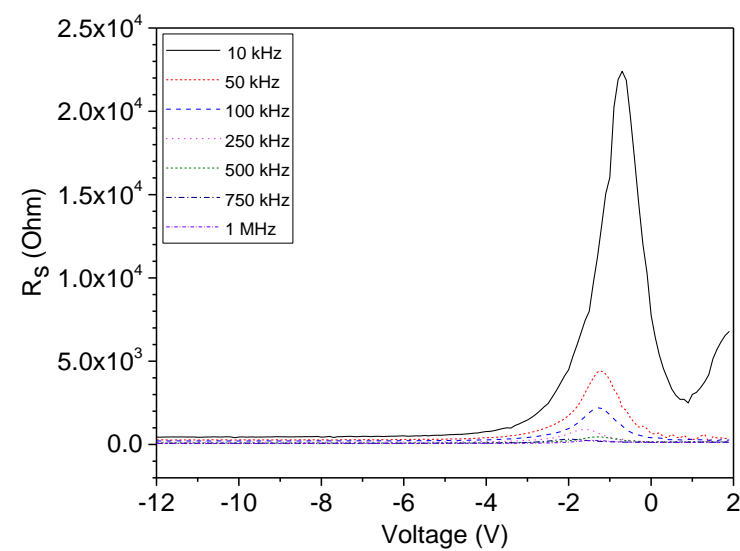

Figure 2. $\mathrm{R}_{\mathrm{s}}-\mathrm{V}$ curves of the $\mathrm{Er}_{2} \mathrm{O}_{3}$ MOS capacitor at different frequencies.

Corrected values are determined when the $\mathrm{R}_{\mathrm{s}}$ effect is removed. The corrected capacitance and conductance values are calculated using the next equations independently of the $\mathrm{R}_{\mathrm{s}}$ effect.

$$
\begin{aligned}
& C_{c}=\frac{\left[\left(G_{m a}\right)^{2}+\left(\omega C_{m a}\right)^{2}\right] C_{m a}}{a^{2}+\left(\omega C_{m a}\right)^{2}} \\
& G_{c}=\frac{\left[\left(G_{m a}\right)^{2}+\left(\omega C_{m a}\right)^{2}\right] a}{a^{2}+\left(\omega C_{m a}\right)^{2}} \\
& a=G_{m}-\left[G_{m a}^{2}+\left(\omega C_{m a}\right)^{2}\right] R_{s}
\end{aligned}
$$

The corrected capacitance-voltage $\left(\mathrm{C}_{\mathrm{c}}-\mathrm{V}\right)$ and corrected conductance-voltage $\left(\mathrm{G}_{\mathrm{c}} / \omega-\mathrm{V}\right)$ curves are shown in Fig. 3 (a)-(b). It is seen that the capacitance values formed by correcting the series resistance effect are increased compared to the previous one. The dielectric constant $\left(\varepsilon_{\mathrm{ox}}\right)$ value calculated from the corrected capacitance curve for $1 \mathrm{MHz}$ was found to be 10.39 , and this value is consistent with the literature $[6,7]$. It is noteworthy that there are considerable variations in the conductancevoltage characteristics when compared with Fig. 1 and Fig. 3 (a). Unobserved conductance peaks with low peak depth before the correction became observable the after correction. Then, the peak values also increased. On the other hand, the conductance is reduced due to the increasing frequency.
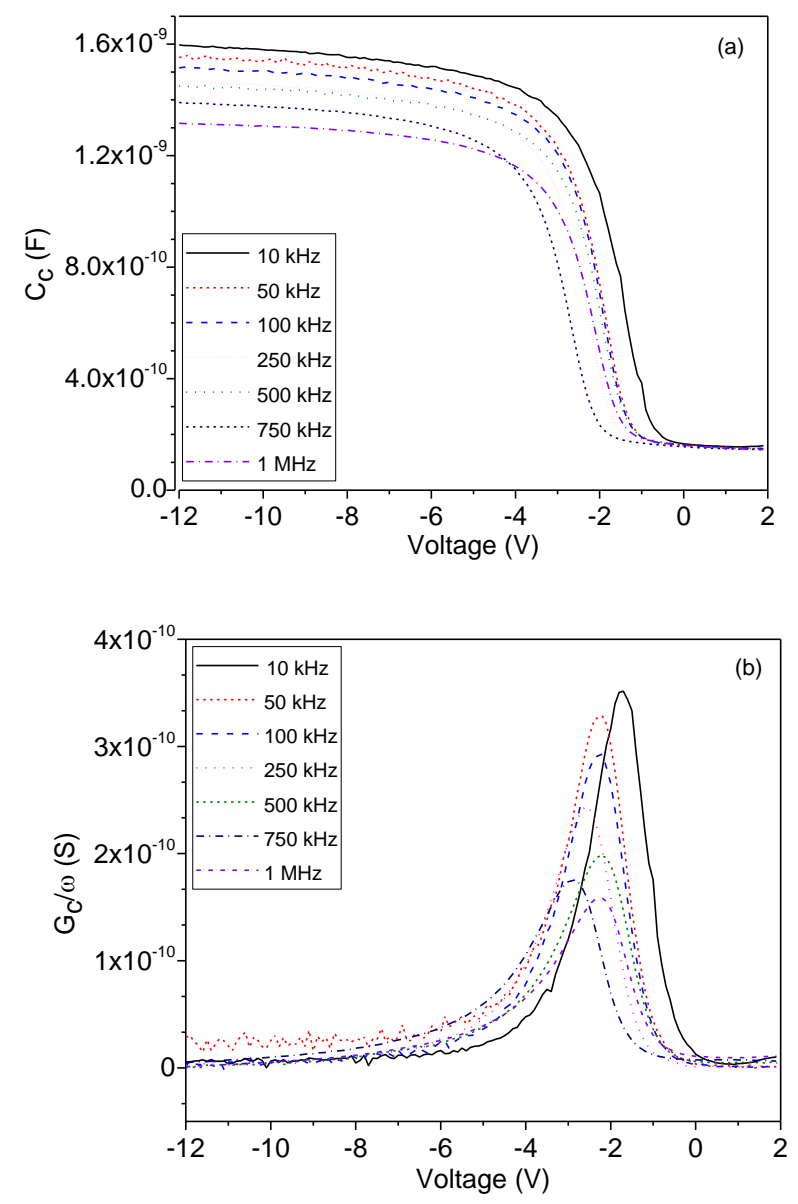

Figure 3. $\mathrm{Er}_{2} \mathrm{O}_{3}$ MOS capacitors: (a) corrected capacitance-voltage characteristics, (b) corrected conductance-voltage characteristics, for frequency range of $10 \mathrm{kHz}-1 \mathrm{MHz}$.

After the corrected capacitance and conductance calculations, the density of interface states $\left(D_{i t}\right)$ may be expressed by the next equation [16].

$$
D_{i t}=\frac{2}{q A} \frac{G_{c, \max } / \omega}{\left(G_{c, \max } / \omega C_{o x}\right)^{2}+\left(1-C_{c} / C_{o x}\right)^{2}}
$$

where $\mathrm{q}$ is elementary charge, $\mathrm{C}_{\mathrm{ox}}$ is the oxide capacitance, $\mathrm{G}_{\mathrm{c} \text {,max }} / \omega$ is peak value of corrected $\mathrm{G} / \omega-\mathrm{V}$ curve, $\mathrm{A}$ is area of MOS capacitor and $C_{c}$ is the corrected capacitance value correspond to $\mathrm{G}_{\mathrm{c}, \max } / \omega$. The values of some required parameters and calculated state density values are given in Table 1. As theoretically predicted $[16,17]$, the interface state densities reduce with enhancement frequency values and are in the order of approximately $10^{12} \mathrm{eV}^{-1} \cdot \mathrm{cm}^{-2}$. 
Table 1. Some electrical parameters for $\mathrm{Er}_{2} \mathrm{O}_{3}$ MOS capacitor.

\begin{tabular}{ccccc}
\hline $\begin{array}{c}\text { Frequency } \\
(\mathrm{kHz})\end{array}$ & $\begin{array}{c}\mathrm{R}_{\mathrm{s}} \\
(\Omega)\end{array}$ & $\begin{array}{c}\mathrm{G}_{\mathrm{c}, \max } \\
\left(\mathrm{x} 10^{-10}\right. \\
\mathrm{S})\end{array}$ & $\begin{array}{c}\mathrm{C}_{\mathrm{c}} \\
\left(\mathrm{x} 10^{-10}\right. \\
\mathrm{F})\end{array}$ & $\begin{array}{c}\mathrm{D}_{\mathrm{it}}\left(\mathrm{x} 10^{11}\right. \\
\left.\mathrm{eV}^{-1} \mathrm{~cm}^{-2}\right)\end{array}$ \\
\hline 10 & 411 & 3.52 & 9.10 & 11.0 \\
\hline 50 & 245 & 3.29 & 8.95 & 11.0 \\
\hline 100 & 211 & 2.93 & 8.67 & 10.4 \\
\hline 250 & 135 & 2.45 & 8.29 & 10.1 \\
\hline 500 & 92 & 1.98 & 7.97 & 9.61 \\
\hline 750 & 71 & 1.76 & 7.51 & 9.27 \\
\hline 1000 & 59 & 1.59 & 7.02 & 8.46 \\
\hline
\end{tabular}

Interface states affecting barrier height are divided into two as acceptor/donor-like interface states [18]. The electrical parameters such as barrier height $\left(\varphi_{\mathrm{B}}\right)$, diffusion potential $\left(\mathrm{V}_{\mathrm{D}}\right)$, and image-force barrier lowering $\left(\Delta \varphi_{B}\right)$ were calculated with the data obtained from the linear regions of the $\mathrm{C}_{\mathrm{c}}{ }^{-2}-\mathrm{V}$ characteristics of the $\mathrm{Er}_{2} \mathrm{O}_{3}$ capacitor are given in Fig. 4 .

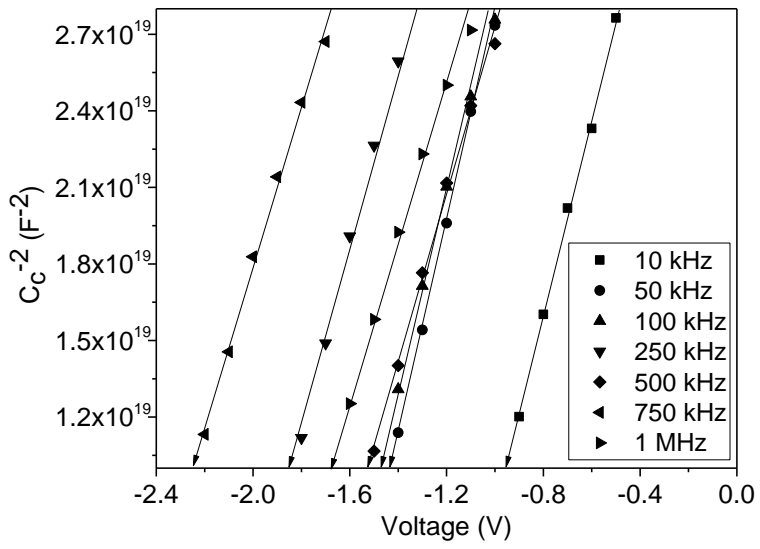

Figure 4. $\mathrm{C}_{\mathrm{c}}{ }^{-2}-\mathrm{V}$ characteristics of the $\mathrm{Er}_{2} \mathrm{O}_{3}$ MOS capacitor in $10 \mathrm{kHz}-1 \mathrm{MHz}$ frequency range.

Capacitance of the depletion regions [19],

$$
C^{-2}=\frac{2\left(V_{0}+V\right)}{\varepsilon_{0} \varepsilon q A^{2} N_{A}}
$$

is given by the Eq. (8) and where $\mathrm{V}$ is the gate voltage, $\mathrm{N}_{\mathrm{A}}$ is the acceptor concentration, $\mathrm{V}_{0}$ is the point intersecting the voltage axis in Fig. $4 . \mathrm{V}_{0}$ is expressed by the following equation.

$$
V_{0}=V_{D}-\frac{k_{B} T}{q}
$$

where $\mathrm{k}_{\mathrm{B}}$ and $\mathrm{T}$ are the Boltzmann constant and absolute temperature, respectively. Barrier height is given by,

$$
\begin{aligned}
\Phi_{B} & =V_{D}+E_{F}-\Delta \Phi_{B} \\
& =V_{D}+\frac{k_{B} T}{q} \ln \left(\frac{N_{V}}{N_{A}}\right)-\Delta \Phi_{B}
\end{aligned}
$$

Where $\mathrm{N}_{\mathrm{V}}$ is the effective state density at the valence band. The maximum value of the electric field is expressed as $E_{m}=\sqrt{2 q N_{A} V_{D} \varepsilon_{s}^{-1} \varepsilon_{0}^{-1}}$. Table 2 shows the values of $\mathrm{E}_{\mathrm{F}}, \varphi_{\mathrm{B}}$ and $\mathrm{N}_{\mathrm{A}}$ obtained for the $\mathrm{Er}_{2} \mathrm{O}_{3}$ MOS capacitor.

Table 2. Other electrical parameters for $\mathrm{Er}_{2} \mathrm{O}_{3} \mathrm{MOS}$ capacitor.

\begin{tabular}{cccc}
\hline $\begin{array}{c}\text { Frequency } \\
(\mathrm{kHz})\end{array}$ & $\begin{array}{c}\mathrm{N}_{\mathrm{A}}\left(\mathrm{x} 10^{15}\right. \\
\left.\mathrm{cm}^{-3}\right)\end{array}$ & $\mathrm{E}_{\mathrm{F}}(\mathrm{eV})$ & $\Phi_{\mathrm{B}}(\mathrm{eV})$ \\
\hline 10 & 1.374 & 0.2399 & 1.4413 \\
\hline 50 & 1.378 & 0.2398 & 1.9445 \\
\hline 100 & 1.512 & 0.2375 & 2.0203 \\
\hline 250 & 1.551 & 0.2368 & 2.3803 \\
\hline 500 & 1.611 & 0.2351 & 2.0740 \\
\hline 750 & 1.765 & 0.2336 & 2.8200 \\
\hline 1000 & 1.885 & 0.2319 & 2.2841 \\
\hline
\end{tabular}

The frequency-dependent barrier height modifications are not anticipated to be in a normal MOS capacitor. The surface energy states that perform as acceptor/donor-like are in the forbidden band. The frequency or radiationinduced states can lead to a change in $\Phi_{B}$ [20]. Therefore, the examination of the barrier height is significant to assess whether the interface states are of the acceptor-like or donor-like type. As shown in Table 2, $\varphi_{\mathrm{B}}$ increased in the frequency range of $10-250 \mathrm{kHz}$. This may be interpreted as the result of more dominant donor-like interface states in structure. After $250 \mathrm{kHz}$, it exhibits an irregular behavior. This irregular behavior may attribute to different behavior of acceptor/donor-like interface states depending on frequency [20].

\section{Conclusion}

In this paper, the electrical characteristics were analyzed at diverse frequencies, with a minimum of $10 \mathrm{kHz}$ and a maximum of $1 \mathrm{MHz}$. The dielectric constant of $\mathrm{Er}_{2} \mathrm{O}_{3}$ was calculated to be 8.39 with the capacitance acquired from the strong accumulation region of measured $\mathrm{C}-\mathrm{V}$ characteristic at $1 \mathrm{MHz}$. The calculated dielectric constant is lower than the values in the literature due to the series resistance effect and no peak is observed in the $\mathrm{G} / \omega-\mathrm{V}$ curve. Therefore, series resistance corrections were made on all measured data. At $1 \mathrm{MHz}$, the dielectric constant calculated the $\mathrm{C}_{\mathrm{c}}-\mathrm{V}$ curve $\left(\varepsilon_{\mathrm{ox}}=10.39\right)$ has been found in accordance with the literature. In other respects, the expected peaks in the conductance-voltage curves were monitored. With the rise in the frequency, the series resistance effect was reduced. The interface states density, which is calculated by using the corrected $\mathrm{C}-\mathrm{V}$ and $\mathrm{G}-\mathrm{V}$ characteristics, reduces with rising frequency. The interface states do not contribute to the capacitance at more than $500 \mathrm{kHz}$ due to there have not sufficient lifetimes to track the A.C. voltage signal. The reason for this is that interface states do not have sufficient time to track the A.C. voltage signal at high frequencies. The decrease in barrier height up to $250 \mathrm{kHz}$ demonstrates that the donor-like interface states are more preponderant over the other states in this range.

\section{Author's Contributions}

Berk Morkoc: Drafted and wrote the manuscript. 
Aysegul Kahraman: Calculated the electrical parameters, did the experiments, and assisted the result interpretation.

Aliekber Aktag: Contributed to the interpretation of the results and prepared the relevant software for the electrical measurements.

Ercan Yilmaz: Supervised the experiment's progress, helped in manuscript preparation, and assisted in analytical calculations.

\section{Ethics}

There are no ethical issues after the publication of this manuscript.

\section{References}

1. Kahraman, A, Yilmaz, E, Aktag, A, Kaya, S. 2016. Evaluation of Radiation Sensor Aspects of $\mathrm{Er}_{2} \mathrm{O}_{3}$ MOS Capacitors under Zero Gate Bias. IEEE Transactions on Nuclear Science; 63(2): 1284 1293.

2. Laha, A, Osten, H.J, Fissel, A. 2007. Influence of Interface Laye Composition on the Electrical Properties of Epitaxial $\mathrm{Gd}_{2} \mathrm{O}_{3}$ Thin Films for High-K Application. Applied Physics Letters; 90 113508-1-3.

3. Kaya, S, Yilmaz, E. 2018. Modifications of Structural, Chemical, and Electrical Characteristics of $\mathrm{Er}_{2} \mathrm{O}_{3} / \mathrm{Si}$ Interface under $\mathrm{Co}-60$ Gamma Irradiation. Nuclear Instruments \& Methods in Physics Research B; 418: 74-79.

4. Kitai, S, Maida, O, Kanashima, T, Okuyama, M. 2003. Preparation and Characterization of High-k Praseodymium and Lanthanoid Oxide Thin Films Prepared by Pulsed Laser Deposition. Japanese Journal of Applied Physics Part 1; 42: 247-253.

5. Pampillon, M.A, Feijoo, P.C, San Andres, E. 2013. High Permittivity Gadolinium Oxide Deposited on Indium Phosphide by High-Pressure Sputtering without Interface Treatments. Microelectronic Engineering; 109: 236-239.

6. Kao, C-H, Chen, H, Pan, Y.T, Chiu, J.S, Luc, T-C. 2012. The Characteristics of the High-K $\mathrm{Er}_{2} \mathrm{O}_{3}$ Dielectrics Deposited on Polycrystalline Silicon. Solid State Communications; 152: 504 508

7. Mao, W, Fujita, M. 2015. Growth of Single-Phase Nanostructured $\mathrm{Er}_{2} \mathrm{O}_{3}$ Thin Films on Si (100) by Ion Beam Sputter Deposition. Surface \& Coatings Technology; 283: 241-246.
8. Kaya, S, Lok, R, Aktag, A, Seidel, J, Yilmaz, E. 2014. Frequency Dependent Electrical Characteristics of $\mathrm{BiFeO}_{3} \mathrm{MOS}$ Capacitors. Journal of Alloys and Compounds; 583: 476-480.

9. Fleetwood, D.M. 1996. Fast and Slow Border Traps in MOS Devices. IEEE Transactions on Nuclear Science; 43: 779-786.

10. Inoue, M, Shimada, A, Shirafuji, J. 1996. Capture Cross Section of Electric-Stress-Induced Interface States in (100) $\mathrm{Si}$ Metal/Oxide/Semiconductor Capacitors. Japanese Journal of Applied Physics Part 1; 35(12A): 5921-5924.

11. Ravotti, F, Glaser, M, Rosenfeld, A.B, Lerch, M.L.E, HolmesSiedle, A.G, Sarrabayrouse, G. 2007. Response of RadFET Dosimeters to High Fluencies of Fast Neutrons. IEEE Transactions on Nuclear Science; 54: 1170-1177.

12. Kahraman, A, Yilmaz, E, Kaya, S, Aktag, A. 2015. Effects of Post Deposition Annealing, Interface States and Series Resistance on Electrical Characteristics of $\mathrm{HfO}_{2}$ MOS Capacitors. Journal of Materials Science-Materials in Electronics; 26(11): 8277-8284.

13. Xiao, H, Huang, S.H. 2010. Frequency and Voltage Dependency of Interface States and Series Resistance in $\mathrm{Al} / \mathrm{SiO}_{2} / \mathrm{p}-\mathrm{Si} \mathrm{MOS}$ structure. Materials Science in Semiconductor Processing; 13: 395.

14. Tataroglu, A, Al-Ghamdi, A.A, El-Tantawy, F. 2016. Analysis of Interface States of $\mathrm{FeO}-\mathrm{Al}_{2} \mathrm{O}_{3}$ Spinel Composite Film/p-Si Diode by Conductance Technique. Applied Physics a Materials Science \& Processing; 122(3): 1-6.

15. Cheung, S.K, Cheung, N.W. 1986. Extraction of Schottky Diode Parameters from Forward Current-Voltage Characteristics. Applied Physics Letters; 49: 85-87.

16. Hill, W.A, Coleman, C.C. 1980. A Single-Frequency Approximation for Interface-State Density Determination. SolidState Electronics; 23(9): 987-993.

17. Tataroglu, A, Altindal, A, Bulbul, M.M. 2005. Temperature and Frequency Dependent Electrical and Dielectric Properties of $\mathrm{Al} / \mathrm{SiO}_{2} / \mathrm{p}-\mathrm{Si}$ (MOS) Structure. Microelectronic Engineering; 81(1): 140-149.

18. Sze, S.M. Physics of Semiconductor Devices; John Wiley and Sons Press: New Jersey, USA, 1981; pp 815.

19. Jaksic, A, Rodgers, K, Gallagher, C, Hughes, P.J. Use of RADFETs for quality assurance of radiation cancer treatments, MIEL 2006-Proceedings, Belgrade, Serbia, 2006, pp 577-579.

20. Kim, M.S, Kim, H.T, Chi, S. 2003. Distribution of Interface States in MOS Systems Extracted by the Subthreshold Current in MOSFETs under Optical Illumination. Journal of Korean Physical Society; 43(5): 873-878. 